\title{
Reticulum Cell Sarcoma of Lymph Node with Mixed Dendritic and Fibroblastic Features
}

Dan Jones, M.D., Ph.D., Mitual Amin, M.D., Nelson G. Ordonez, M.D., Armand B. Glassman, M.D., Kimberly J. Hayes, B.S., L. Jeffrey Medeiros, M.D.

Division of Pathology and Laboratory Medicine, University of Texas-M.D. Anderson Cancer Center, Houston, Texas

We report a case of clinically aggressive reticulum cell sarcoma with mixed follicular dendritic cell (FDC) and fibroblastic reticular cell (FRC) features. Histologically, the tumor was confined to lymph nodes occurring as a multifocal epithelioid and spindle cell proliferation with appreciable mitotic rate and numerous admixed non-neoplastic B-cells. Ultrastructural examination revealed elongated cells with prominent nucleoli, interdigitating cell processes and frequent desmosomes. These features are typical of FDC sarcoma. However, immunohistochemical stains showed no expression of antigens characteristic of FDCs, including CD21, CD23 and CD35. Cytogenetic characterization of this tumor, by conventional G-banding and multicolor spectral karyotyping, revealed multiple clonal chromosomal aberrations, including $\operatorname{del}(\mathrm{X})(\mathrm{p} 11.4)$ and add (21)(p11.2). Gene expression analysis by cDNA microarray of RNA obtained from short-term tumor cultures revealed high-level expression of a set of genes (including PDGF receptor- $\alpha$ and $-\beta$, certain metalloproteinases, and $\mathrm{CD105)}$ that were also highly expressed in cultures of nodal FRC cultured from non-neoplastic lymph nodes. We propose that this tumor represents a nodal sarcoma with intermediate differentiation between FDCs and FRCs. This case adds to the diversity of tumors that may arise from lymph node stroma and supports a possible relationship between the FDC and FRC lineages.

KEY WORDS: Dendritic cell, Fibroblast, Lymph node, Sarcoma.

Mod Pathol 2001;14(10):1059-1067

Copyright (C) 2001 by The United States and Canadian Academy of Pathology, Inc.

VOL. 14, NO. 10, P. 1059, 2001 Printed in the U.S.A

Date of acceptance: June 6, 2001.

Address reprint requests to: Dan Jones, M.D., Ph.D., Department of Hematopathology, Box 72, UT-M.D. Anderson Cancer Center, 1515 Holcombe Blvd., Houston, TX 77030; e-mail: dajones@mdanderson.org; fax: 713-745-0736.
Lymph nodes contain a heterogeneous population of stromal cells with reticular morphology. These include antigen-presenting follicular dendritic cells (FDC) within the lymphoid follicle; interdigitating reticular cells (IDCs) related to the myeloid/monocytic lineage, and interfollicular fibroblastic reticular cells (FRCs) of mesenchymal origin (1-4). The FDC population includes multiple immunophenotypically distinct subsets of stromal cells within the lymphoid follicle and mantle zone that regulate distinct stages of B cell differentiation $(5,6)$. IDCs have a primary function in antigen presentation in the interfollicular zones of the node and differentiate from Langerhans cells migrating from skin or from bone marrow-derived precursors (2). FRCs form a diffuse extrafollicular network that guides cell migration within the lymph node (7).

Nodal sarcomas have been described that are postulated to arise from each of these different reticular cell populations. These include CD21- and CD35-positive FDC sarcoma (8) and S100-positive IDC sarcoma (9-12). Recently, several groups have reported nodal sarcomas of possible FRC lineage (13-15). However, some of these tumors have been incompletely studied, with only limited antigen profiling and ultrastructural analysis. Thus, the range of features associated with FRC sarcoma is not yet clearly delineated. Here, we report the first morphologic, extended phenotypic and genotypic characterization of a case of primary lymph node sarcoma with mixed dendritic and fibroblastic features.

\section{METHODS}

Hematoxylin and eosin-stained histologic sections from the original biopsy specimen obtained at an outside hospital were compared with the initial resection and tumor recurrence specimens, both done at our institution. Clinical information was obtained from the medical record. 
Immuohistochemistry and Electron Microscopy

Immunostains were performed on formalinfixed, paraffin-embedded tissue sections using the avidin-biotin-peroxidase complex method in a DAKO Autostainer (Carpinteria, CA). Sections were stained with monoclonal antibodies to vimentin (V9, DAKO, 1:25 dilution), desmin (D33, DAKO, 1:100), smooth-muscle actin (1A4, DAKO, 1:3,000), muscle actin (HHF35, DAKO, 1:3000), CD1a (NA1/34, Immunotech, Westbrook, ME, neat), CD5 (4C7, Novocastra, Newcastle upon Tyne, U.K.), CD20 (L26, DAKO, 1:100), CD21 (1F8, DAKO, 1:50), CD23 (1B12, Novocastra, 1:15), CD31 (JC/70A, DAKO, 1:200), CD35 (Ber-MAC-DRC, DAKO, 1:10), CD40 (11E9, Novocastra, 1:20), CD54/Intercellular adhesion molecule-1 (Pharmingen, 1:10), CD68 (KP-1, DAKO, 1:100), CD105 (SN6h, Pharmingen, 1:10), CD106/ Vascular cell adhesion molecule-1 (VCAM-1, DAKO, 1:25), ALK kinase (ALK1, DAKO, 1:10) and CNA.42 (FDRC, Beckman Coulter, Fullerton, CA, neat). Tissue was also stained with a cocktail of three anti-cytokeratin monoclonal antibodies (AE1 and AE3, Boehringer-Mannheim, Indianapolis, IN, 1:200 and CAM 5.2, Becton-Dickinson, Mountainview, CA 1:5) that recognize a wide range of high and low molecular weight cytokeratin peptides, and with polyclonal antibodies raised in rabbits to CD3 (DAKO, 1:100), and S-100 protein (DAKO, 1:700). The immunostaining was done using the LSAB2 peroxidase kit (DAKO). To enhance the immunostaining, a heat-induced epitope retrieval procedure was performed using a Black-and-Decker vegetable steamer with citrate buffer solution, $\mathrm{pH}$ 6.0. The antigenantibody reaction was visualized using 3 -amino9-ethylcarbazole or diaminobenzidine. Nonneoplastic lymph nodes were used to assess the immunohistochemical staining patterns of the above markers in nodal FRC and FDC. Immunohistochemical analyses of cultured cells was performed on subconfluent monolayers seeded in multi-well tissue culture slides, and fixed for 2 minutes in situ with 5\% buffered formaldehyde or methanol, followed by immunostaining as above.

For electron microscopy studies, tissue samples from the initial resection specimen and recurrence were fixed in $2 \%$ glutaraldehyde, postfixed in $1 \%$ osmium tetraoxide and embedded in Epon epoxy resin. Ultrathin sections were stained with uranyl acetate and lead citrate.

\section{Cell Culture}

Tumor cells from grossly involved portions of fresh lymph node were disaggregated, treated with collagenase and seeded in Dulbecco's modified Eagle's media with $20 \%$ fetal bovine serum and L-glutamine. Adherent cells from the primary tu- mor samples were passaged and later cloned by limiting dilution to establish a pure tumor cell population. The relationship of the passaged material to the original tumor was investigated by cytogenetic analysis. For comparison of gene expression pattern, identical short-term stromal cultures were similarly established from disaggregated stroma from benign lymph nodes of four different patients. Under these culture conditions, there was selective expansion of fibroblastic-appearing stromal subsets. Lymphoid, macrophage and terminally-differentiated dendritic cell populations were not maintained in culture by passage 3 (DJ, unpublished).

\section{Karyotypic Analysis}

Cytogenetic analysis was performed on a fresh sample of tumor obtained from disaggregated tissues, cultured for 4 days (in the absence of mitogens) with harvest of the adherent cell population. Karyotypic analysis of G-banded metaphases was performed according to standard procedures. Multicolor spectral karyotypic analysis (SKYTM) was subsequently performed on the G-banded metaphases following hybridization with 24 fluorescently-labeled chromosome painting probes (16). Spectral classification of each chromosome was automatically performed by the imaging software and a discrete pseudo-color assigned to all pixels within a given spectrum. Image acquisition was performed using a SD 200 Spectracube (Applied Spectral Imaging, Carlsbad, CA) using a custom designed optical filter. The SKY display image was compared with the G-banded karyotype to confirm the automated chromosomal assignments.

\section{Transcriptional Profiling}

Total cellular RNA was extracted from adherent cell monolayers (passage 2) using guanidinium solubilization/column purification (Ambion, Austin, TX). cDNA was obtained by reverse transcription of $2 \mu \mathrm{g}$ of total RNA with AMV-reverse transcriptase and ${ }^{33} \mathrm{P}$-labeled nucleotides using gene-specific primers and hybridized to a commercially-available nylon filter gene array containing $~ 375$ cytokine and adhesion genes ("cytokine" array from $R \& D$ Systems, Minneapolis, MN). These filters contain duplicate spots for each gene as well as nine housekeeping genes for normalization of transcript level. Expression was quantified following autoradiography with correction for background signal and normalization to the level of expression of the housekeeping gene cyclophilin A. Data analysis performed with ArrayVision software (Imaging Resources, Ontario, Canada). Data were obtained 
from two separate cDNA labeling/hybridizations produced from the same RNA samples. For comparison of gene expression, passage 4 cultures from adherent stromal cultures from non-neoplastic lymph nodes were established from four patients. RNA was also extracted from these non-neoplastic lymph nodes and subjected to parallel hybridization with the same "cytokine" cDNA array.

\section{RESULTS}

\section{Case Report}

The patient was a 25-year-old white male who presented with a left neck mass in November 1996. Radiographic studies revealed a dominant galliumavid nodal-based left perithyroidal mass and multiple mildly enlarged lymph nodes in the inferior/ deep jugular area. There was no radiographic evidence of lung involvement, abdominal disease or soft tissue or bony abnormalities. Biopsy revealed a malignant neoplasm, and the patient was referred to UT-M. D. Anderson Cancer Center for definitive resection. Partial thyroidectomy, thymectomy, bilateral selective neck and superior mediastinal lymph node dissection demonstrated tumor involvement of multiple regional lymph nodes, including bilateral cervical, mediastinal, paratracheal and paraesophageal areas. Thyroid and thymus were negative for tumor. Postoperatively, the patient received six cycles of cyclophosphamide, doxorubicin, vincristine, and prednisolone chemotherapy and radiation to the anterior neck and chest (total of $40 \mathrm{~Gy}$ in 22 fractions). The patient represented in October 2000 with evidence of a recurrent superior mediastinal mass. Resection documented multifocal involvement of regional lymph nodes, predominantly paratracheal and paracaval, with no evidence of extranodal disease. The patient is currently 54 months following initial presentation undergoing adjuvant chemotherapy with ifosfamide and VP-16 with no radiologic evidence of recurrence.

\section{Histologic and Ultrastructural Findings}

The initial biopsy, resection and recurrence specimens showed similar histologic features. Numerous lymph nodes were partially to completely effaced by a tumor with mixed spindle, epithelioid and dendritic morphology. Tumor cells had vesicular nuclei with prominent nucleoli and long cytoplasmic processes that enveloped numerous small lymphocytes (Fig. 1). Focally, tumor cells showed nodular aggregation simulating follicles. The mitotic count was 25 and 21 per 10 high power fields in the initial and recurrent biopsy, respectively. No histologic involvement of the thymus or thyroid

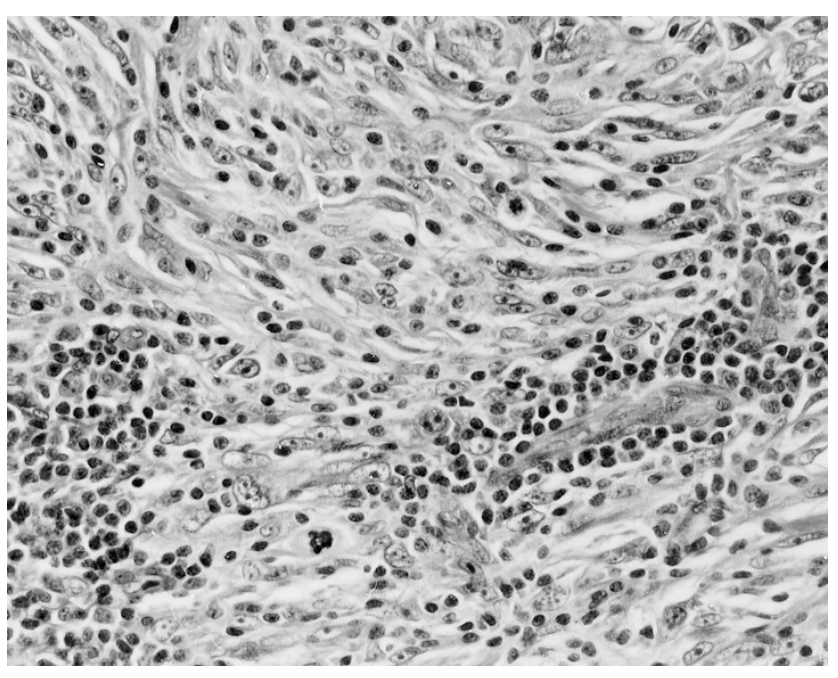

FIGURE 1. Nodal stromal sarcoma. Spindled tumor cells with vesicular nuclei, prominent nucleoli and abundant cytoplasm are admixed with frequent lymphocytes (Hematoxylin and eosin).

glands was seen. In the tumor recurrence, one $3 \mathrm{~cm}$ involved lymph node was completely necrotic. Cytologic features assessed on touch preparations of the tumor recurrence revealed large, polygonal cells with eosinophilic cytoplasm and delicate dendritic processes, in a background of small round lymphocytes (Fig. 2).

Ultrastructural analysis was performed on both the initial and recurrent tumor. Elongate, tightly packed tumor cells were noted that had abundant interdigitating cytoplasmic processes and frequent well-developed desmosomes (Fig. 3). Basal lamina, tonofilaments, melanosomes and secretory granules were absent. Ultrastructural analysis of the recurrent tumor showed similar features with welldeveloped desmosomes and cell processes but with more prominent nucleoli and more frequent interspersed lymphoid cells (not shown).

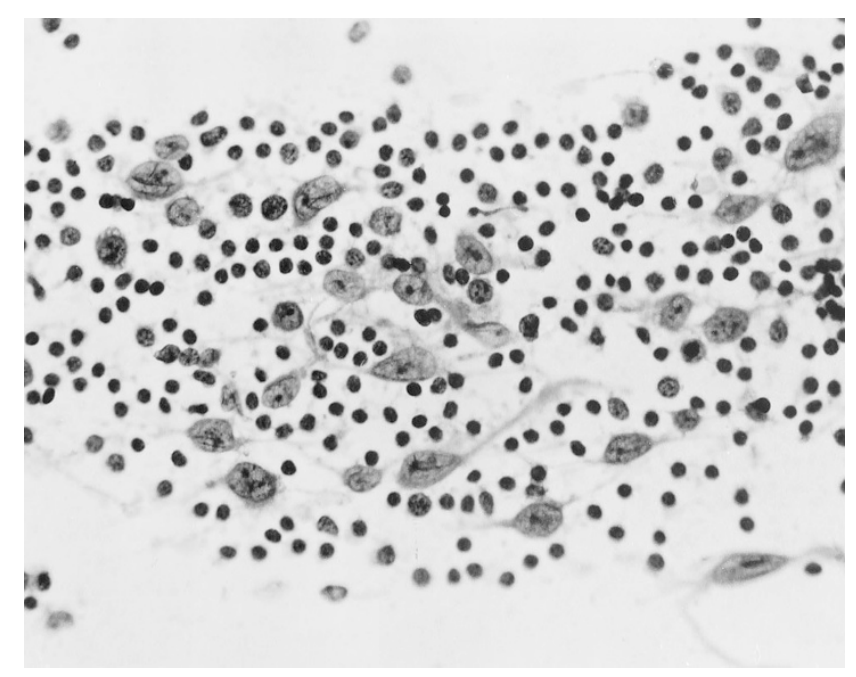

FIGURE 2. Cytologic features. Large tumor cells with fine dendritic processes intermixed with small lymphocytes (Wright stain). 


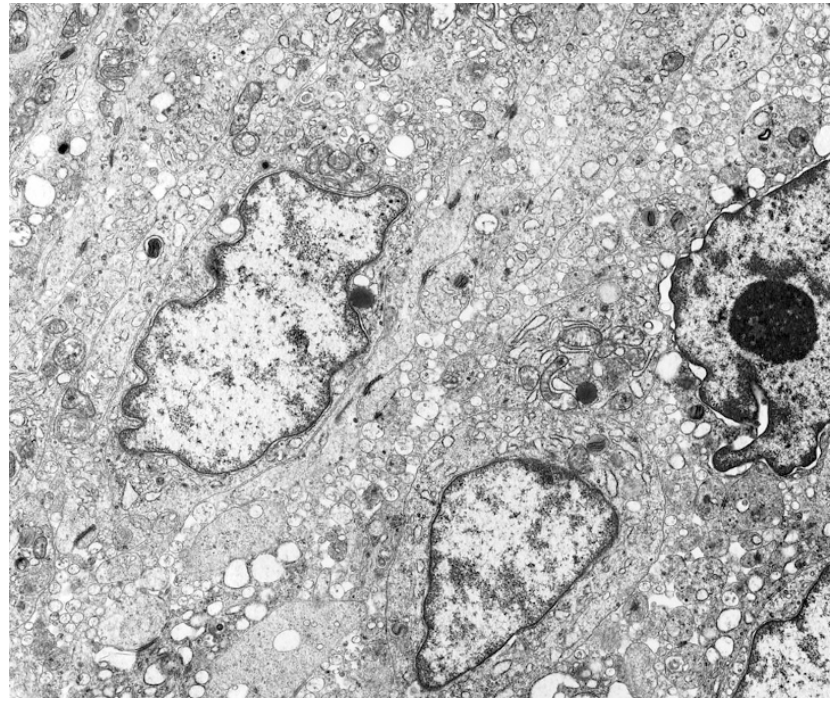

FIGURE 3. Ultrastructural features. Spindled tumor cells are noted with tightly opposed interdigitating cell processes and an absence of basal lamina or abundant extracellular matrix. Numerous well-formed desmosomes are noted.

Immunophenotypic Findings (see Table 1)

Tumor cells in both the initial biopsy and reexcision specimens were negative for the FDCassociated markers CD21, CD23, CNA.42 and CD35, which were positive only in adjacent residual reactive follicles $(17,18)$. An expanded immunohistochemical profile done on the recurrence showed that the neoplastic cells were strongly positive for vimentin, CD40 and VCAM-1 with rare cells positive for the actin-bundling protein, fascin (Fig. 4 and data not shown). VCAM-1 staining was most prominent in tumor cells with a dendritic appearance and CD40 was strongest in those areas with an epithelioid morphology. The tumor cells were negative for CD3, CD5, CD20, CD31, keratin cocktail, desmin, ALK, S-100, smooth muscle actin, and HHF-35. Rare tumor cells were positive for CD45RB/LCA. Table 1 is a comparison of staining patterns observed in the tumor with that seen in non-neoplastic nodal stromal cells in reactive lymph nodes.

A remarkable feature of the tumor in both the initial and recurrent specimens was the presence of numerous admixed non-neoplastic lymphocytes. These cells were most prominent in the spindled/ dendritic tumor cells (Fig. 4A) and were almost all CD20-positive B-lymphocytes. Most of these tumor-associated B cells coexpressed the activation markers CD23 and CD40 and were negative for CD5 (not shown).

\section{Cytogenetic Findings}

Metaphases prepared from short-term stromal cultures revealed multiple complex clonal chromosomal aberrations in 20 of 24 analyzed metaphases, including hypertetraploid (chromosome number 101-116), hyperdiploid (chromosome number 5557) and pseudodiploid populations. Given the complexity of the karyotype, spectral analysis was done to assist with assignment of chromosomal order. SKY detected variations in individual chromosome copy number as well as multiple clonal chromosomal rearrangements including three-way translocations involving chromosomes 6, 9, and 17 and chromosomes 2, 6, and 13, and translocations involving $X$ and 7,1 and 20, 2 and 22, 10 and 15, 14 and 16, 11 and 15, and 21 and 22. The display image from a SKY analysis of one such hypertetraploid tumor cell is shown in Figure 5. The $t(X ; 7)$ and $t(21 ; 22)$ translocations were also clearly seen in the G-banded karyotype, and involved $\operatorname{del}(\mathrm{X})(\mathrm{p} 11.4)$ and add (21)(p11.2). Some of the remaining translocations and marker chromosomes were too complex to be recognized by conventional analysis.

\section{Gene Expression Analysis}

We performed cDNA microarray analysis on RNA isolated from short-term cultures of tumor cells to
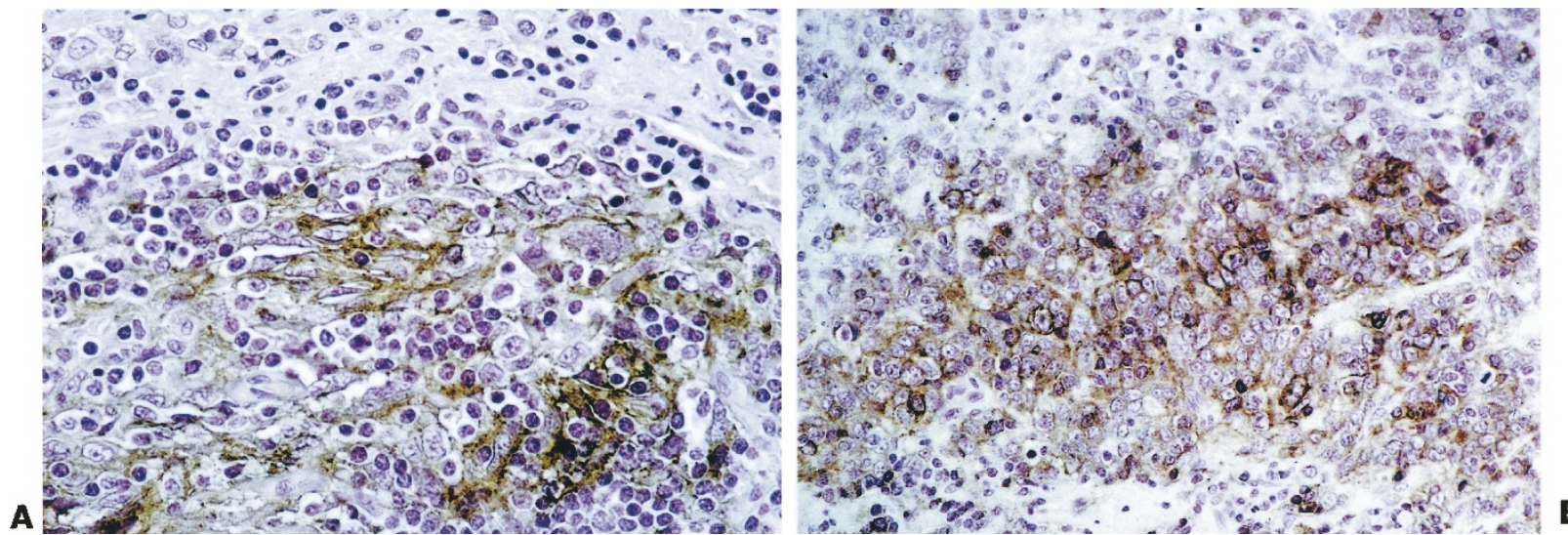

FIGURE 4. (A) Tumor cells, with a dendritic morphology, are strongly immunoreactive for VCAM-1. (B) CD40 immunostain is positive in tumor cells with an epithelioid morphology. 
TABLE 1. Comparison of Antigen Expression in this Tumor as Compared with Nodal FRC Cultures, Contrasted with the Reported Phenotypes for Other Lymph Node Sarcomas and Dendritic Cells

\begin{tabular}{|c|c|c|c|c|c|c|}
\hline & \multicolumn{2}{|c|}{ From this Study } & \multicolumn{4}{|c|}{ From a Review of the Literature ${ }^{a}$} \\
\hline & Tumor Culture & FRC Culture & Normal FDC & FDC Sarcoma & Normal IDC & IDC Sarcoma \\
\hline \multicolumn{7}{|l|}{ FDC-associated } \\
\hline $\mathrm{CD} 21^{\mathrm{b}}$ & - & - & ++ & ++ & - & - \\
\hline CD23 & - & - & ++ & ++ & - & - \\
\hline CD35 & - & - & ++ & ++ & - & - \\
\hline CNA. 42 & Rare & - & ++ & ++ & - & - \\
\hline $\mathrm{CD} 40^{\mathrm{b}}$ & ++ & Weak + & ++ & ++ & - & - \\
\hline CD106/VCAM- $1^{\mathrm{b}}$ & ++ & - & ++ & $\mathrm{nr}$ & - & $\mathrm{nr}$ \\
\hline \multicolumn{7}{|l|}{ IDC-associated } \\
\hline S100 & - & - & $\mathrm{v}+$ & $\mathrm{v}+$ & ++ & ++ \\
\hline $\mathrm{CD}_{1} \mathrm{a}^{\mathrm{b}}$ & - & - & - & - & $\mathrm{v}+$ & $\mathrm{v}+$ \\
\hline \multicolumn{7}{|l|}{ Mesenchymal markers } \\
\hline CD105 (endoglin) ${ }^{\mathrm{b}}$ & $\mathrm{v}+$ & Rare & - & $\mathrm{nr}$ & - & $\mathrm{nr}$ \\
\hline Fascin & $\mathrm{v}+$ & $\mathrm{v}+$ & + & $\mathrm{nr}$ & ++ & $\mathrm{nr}$ \\
\hline $\begin{array}{l}\text { Muscle actin } \\
\text { (HHF35) }\end{array}$ & - & + & - & $\mathrm{nr}$ & - & $\mathrm{nr}$ \\
\hline $\begin{array}{l}\text { Smooth-muscle } \\
\text { actin }\end{array}$ & - & $\mathrm{v}+$ & - & - & - & - \\
\hline Desmin & - & $\mathrm{v}+$ & - & - & - & - \\
\hline Vimentin & ++ & ++ & $\mathrm{v}+$ & $\mathrm{v}+$ & - & + \\
\hline \multicolumn{7}{|l|}{ Other markers } \\
\hline Keratin $^{c}$ & - & $\mathrm{v}+$ & - & - & - & - \\
\hline CD54/ICAM-1 ${ }^{\mathrm{b}}$ & + & $\mathrm{v}+$ & + & $\mathrm{nr}$ & & $\mathrm{nr}$ \\
\hline CD68 & + & $\mathrm{v}+$ & - & $\mathrm{v}+$ & - & + \\
\hline
\end{tabular}

Expression pattern in tumor and normal stromal populations derived from immunohistochemical staining of paraffin sections of tumor and non-neoplastic human lymph node and tonsil samples. Immunoreactivity graded as ++ (uniform, strong), + (partial or moderate), v + (variable, weak), and - (negative).

${ }^{a}$ Expression patterns for FDC and IDC sarcomas based on consensus of previously reported cases $(8,12,17,22,23,26,27,30,44,45)$.

${ }^{b}$ Indicates that immunohistochemical staining pattern was correlated with that seen by cDNA array transcriptional analysis of short-term stromal cell cultures of tumor and of fibroblastic stroma from non-neoplastic lymph node. See text for more details.

${ }^{c}$ Keratin cocktail used here detects the keratin 8/18-positive subset of non-neoplastic nodal FRC.

FRC, fibroblastic reticular cell; FDC, follicular dendritic cell; IDC, interdigitating reticular cell; nr, not reported; VCAM-1, vascular cell adhesion molecule-1; ICAM-1, intercellular cell adhesion molecule-1; EMA-epithelial membrane antigen.

assess expression of 375 well-characterized adhesion and growth regulatory genes. Transcript level measured by signal strength on the array was compared with immunohistochemical expression of certain markers in the cultured tumor cells and the original tumor sample for validation (summarized in Table 1).

Aside from housekeeping genes and some integrin receptors, cultured tumor cells showed the most intense hybridization signals for genes characteristically expressed in mesenchymal cells/fibroblasts including the adhesion molecules cadherin-11, decorin and endoglin (CD105), the insulin growth factor binding proteins $4-8$, the metalloproteinases MMP-1, MMP-14, TIMP-1, TIMP-2 and TIMP-3, and the receptor tyrosine kinases PDGFR- $\alpha$ and $-\beta$, oncostatin receptor beta and bone morphogenetic receptor IIA. All of these genes were also highly transcribed in four FRC stromal cultures established from four different non-neoplastic lymph nodes (data not shown). In contrast, most arrayed genes characteristic of normal FDC showed low or undetectable signals in the tumor cell sample, including CD21, IL-13 receptor, and the FDC-associated chemokine BLC/BCA-1 (21). Transcription of the lymphocyte chemoattractants MCP-1, MIP-3 $\beta$, and SDF-1 was also noted in both tumor and non-neoplastic FRC stromal samples.

Of the 375 tested, the adhesion molecules $\mathrm{N}$-cadherin and Intercellular adhesion molecule-3 (highly expressed in normal FDC $[19,20]$ ) were the only two genes whose signal was more than 5 -fold higher in the tumor cultures as compared with the nodal fibroblast cultures. No arrayed genes were noted that were highly transcribed in the nonneoplastic nodal fibroblastic cultures but not in the tumor sample.

For most tested genes, the results of immunostaining of fresh cultured tumor cells correlated with the level of transcripts detected by cDNA array and the immunostaining results on the histologic sections from the tumor. We confirmed expression of vimentin, PDGFR- $\alpha$, and CD105 (weak) and absence of staining for CD21 and CD23 in the cultures and the tumor tissue.

The immunostaining pattern in the tumor cultures did show some differences compared with the in vitro tumor cultures. In particular, we noted an absence of immunostaining (and only a weak hybridization signal on the array) for both CD40 and VCAM-1 despite the strong immunostaining for these markers in a subset of the original tumor cells (Fig. 4). These results indicate that there was either 


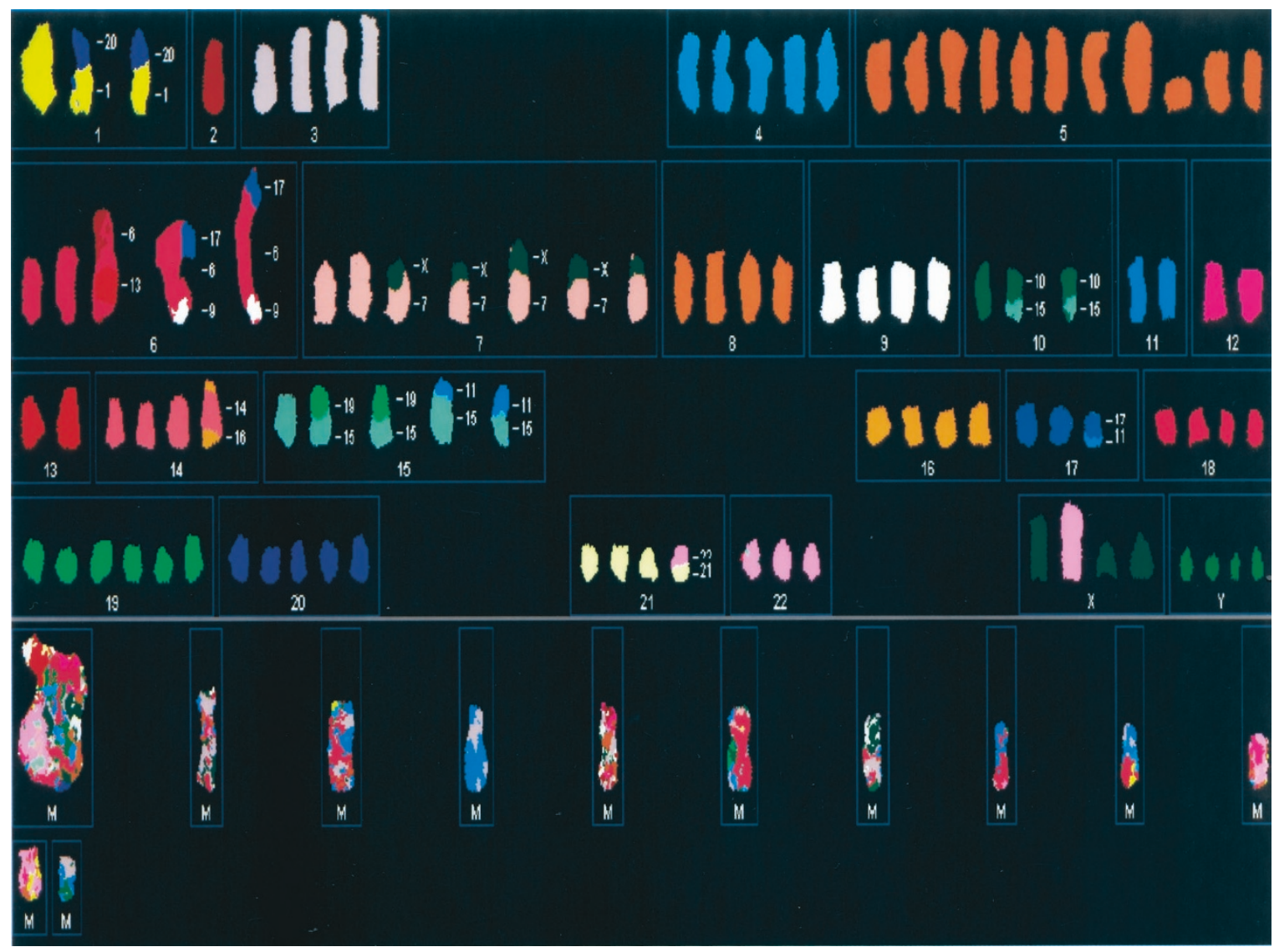

FIGURE 5. Multicolor spectral karyotyping (SKY) of short-term stromal cultures of tumor reveal complex clonal chromosomal aberrations. Assignment of chromosomes by spectral analysis software was confirmed by comparison with G-banded karyotype on the same material.

selective outgrowth of the CD40 ${ }^{-}$, VCAM-1 ${ }^{-}$subset of tumor cells or modulation of the expression of some genes during growth in culture.

\section{DISCUSSION}

We present a case of a recurrent lymph node spindle cell tumor arising in a young man that shows mixed features of FDC and FRC sarcoma. The differential diagnosis of nodal sarcoma includes both primary tumors (FDC, FRC, IDC, and inflammatory myofibroblastic tumors) and metastatic soft tissue tumors. In this case, the multifocal involvement of numerous lymph nodes and absence of any extranodal lesions over the 3-year disease course strongly argues for primary nodal origin. Given the mediastinal location, sarcomatoid thymic carcinoma was a diagnostic consideration but was excluded based on absence of keratin immunostaining and the resected uninvolved thymus. Inflammatory myofibroblastic tumor and IDC sarcoma were excluded based on morphologic features and the absence of smooth-muscle actin, ALK and S100 staining, respectively.

Among nodal sarcomas, ultrastructural features traditionally have been used as the most definitive evidence of differentiation. FDC sarcomas are char- acterized by interdigitating spindle cells with welldeveloped desmosomes and a lack of cytoplasmic filaments $(8,22,23)$. IDC sarcomas typically have branching and interdigitating processes with an absence of cell junctions $(9,10)$. Ultrastructural studies on nodal FRC sarcoma are few and have shown variable features $(14,15,24)$. The keratin-positive subset of FRC sarcoma can apparently show both desmosomes and tonofilaments $(13,15)$. A characteristic feature of non-neoplastic FRC is their envelopment of extracellular collagen/reticular fibers; FRC can also show variable myofibroblastic features with dense bodies (4). Ultrastructural features of other specialized nodal stromal populations, such as sinusoidal lining cells have been reported (25), but tumors postulated to arise from these subsets have not been reported to date. In the current case, the presence of numerous desmosomes and the absence of tonofilaments or ultrastructural features of myofibroblasts (e.g., dense bodies and basal lamina) or fibroblasts (e.g., abundant collagen or prominent endoplasmic reticulum) are most similar to FDC sarcoma.

Immunophenotypic studies have demonstrated reproducible patterns of differential antigen expression in nodal sarcomas. Like their non-neoplastic counterpart, FDC sarcomas have shown strong uni- 
form positivity for CD21, CD23 and CD35 in nearly all reported cases $(8,22,26,27)$. In these tumors, CD21 staining is detected with antibodies (e.g., DRC-1, R4/23 and Ki-M4) that preferentially recognize the FDC-associated isoform (CD21L) that is not expressed by B cells $(26,28,29)$. Only a few cases with morphologic features of FDC sarcoma have been reported that lack both CD21 and CD35 immunoreactivity $(17,30)$. Some investigators have reported expression of CD45 (weak), B cell markers CD19, CD20, CD22, EMA or CD4 on cases of FDC sarcoma $(8,27)$. It is likely, however, that some of these lymphoid-associated antigens are not produced by the tumor cells but are present on the numerous intermixed reactive cells or displayed/ absorbed on the surface of the tumor. Single cell expression studies have not detected the transcription of a number of these lymphoid markers in normal FDC (31). The range of antigen expression in FRC sarcoma has not been well defined. Nonneoplastic nodal FRC show uniform positivity for vimentin with subsets positive for actin, desmin, CD68 and keratin (32-36). However, the markers vimentin and CD68, also expressed in this case, are not lineage-specific and can be expressed in a variety of nodal sarcomas (see Table 1).

The case presented here had no immunohistochemical evidence of well-defined markers of FDC differentiation, such as CD21, CD23, or CD35. Tumor cells did express CD40 and CD106/VCAM-1; two markers strongly expressed in normal FDC but at lower levels in most fibroblasts. However, the range of other highly expressed genes in cultured tumor cells was nearly identical to that seen in non-neoplastic nodal fibroblasts and supports a FRC sarcoma phenotype. The cytokine and chemokine profile of the cultured tumor cells was also similar to the FRC cultures with absence of transcription of the FDC-associated chemokine BLC/ BCA-1 (21) and the cytokine receptor IL-13 receptor. We did note some modulation of expression of some genes in the short-term tumor cultures as has been previously shown for cultured FDC (37-39). Nonetheless, we noted a good correlation between the staining patterns of other markers by immunostains on sections of the tumor and the transcription detected by cDNA arrays on cultured material.

Karyotypic analysis of the tumor recurrence revealed multiple complex clonal aberrations, many of which were not initially interpretable on conventional G-banding. SKY analysis was helpful in uncovering the chromosomal partners in a number of translocations. However, even with this technique, the origin of some of the aberrant chromosomes could not be identified (listed as markers in Fig. 5). To our knowledge, this is the first karyotype of a nodal sarcoma reported so no comparison with previous tumors could be made. The specific recip- rocal rearrangements seen here are not typical of any other sarcoma type.

In this tumor, we have noted numerous admixed non-neoplastic B cells expressing CD23, in both the primary sample and tumor recurrence. Previous studies have noted that admixed reactive lymphocytes are a consistent feature of FDC sarcoma but have not commented on the phenotype of these cells. This finding, which is reminiscent of the association of follicular B-cells with FDC, could be mediated by tumor cell expression of B-cell proliferative, chemotactic or adhesive factors. In this regard, we detected high level transcription of the B-cell growth-stimulatory cytokine IL-6, but an absence of transcription for the FDC-associated chemokine, BLC/BCA-1, involved in B cell homing to the follicle (21). Transcription of two other B-cell chemoattractants, stromal derived factor-1 (SDF-1) and MIP-3 $\beta$ was noted, however, in the tumor cultures. Finally, especially in the more dendritic areas of the tumor, we noted high level expression of VCAM-1, which has a primary role in mediating binding of VLA-4-expressing B-cells to FDC in the germinal center (40).

The histogenesis of FDCs remains controversial. Ultrastructural comparisons and mouse bone marrow transplantation studies have favored differentiation from local populations of mesenchymal cells (i.e., FRCs or mesenchymal precursors) $(5,41)$. Tissue culture studies have shown that cytokines can induce expression of FDC markers in undifferentiated mesenchymal cells $(42,43)$. Our case is of interest in this regard because the morphologic and ultrastructural appearances of the tumor are most similar to FDC sarcoma. However, the antigen expression profile lacks many features of FDC and is more consistent with a fibroblastic phenotype. This tumor highlights the relationship between these reticular cell types and demonstrates that stromal cell sarcomas with a mixed lineage and/or intermediate differentiation occur and may be more common than previously recognized. Complete delineation of the differences between FDC and FRC sarcoma will await further characterization of the phenotype of their non-neoplastic lymph node counterparts. It is likely that the phenotypic variation exhibited by nodal sarcomas will be reflected by phenotypic diversity in these normal nodal stromal populations.

Acknowledgments: The authors thank Wen-Hua Lang and Thomas Brooks for assistance with immunohistochemical studies and expression analysis.

\section{REFERENCES}

1. Cyster JG, Ansel KM, Reif K, et al. Follicular stromal cells and lymphocyte homing to follicles. Immunol Rev 2000;176:18193. 
2. Santiago-Schwarz F. Positive and negative regulation of the myeloid dendritic cell lineage. J Leukoc Biol 1999;66:209-16.

3. Anderson AO, Shaw S. T cell adhesion to endothelium: the FRC conduit system and other anatomic and molecular features which facilitate the adhesion cascade in lymph node. Semin Immunol 1993;5:271-82.

4. Tykocinski M, Schinella RA, Greco MA. Fibroblastic reticulum cells in human lymph nodes. An ultrastructural study. Arch Pathol Lab Med 1983;107:418-22.

5. Heinen E, Bosseloir A, Bouzahzah F. Follicular dendritic cells: origin and function. Curr Top Microbiol Immunol 1995;201:15-47.

6. Imai Y, Maeda K, Yamakawa M, et al. Heterogeneity and cellular origin of follicular dendritic cells. Adv Exp Med Biol 1993;329:339-44.

7. Gretz JE, Norbury CC, Anderson AO, Proudfoot AE, Shaw S. Lymph-borne chemokines and other low molecular weight molecules reach high endothelial venules via specialized conduits while a functional barrier limits access to the lymphocyte microenvironments in lymph node cortex. J Exp Med 2000;192:1425-40.

8. Chan JK, Fletcher CD, Nayler SJ, Cooper K. Follicular dendritic cell sarcoma. Clinicopathologic analysis of 17 cases suggesting a malignant potential higher than currently recognized. Cancer 1997;79:294-313.

9. Rousselet MC, Francois S, Croue A, Maigre M, Saint-Andre JP, Ifrah N. A lymph node interdigitating reticulum cell sarcoma. Arch Pathol Lab Med 1994;118:183-8.

10. Rabkin MS, Kjeldsberg CR, Hammond ME, Wittwer CT, Nathwani B. Clinical, ultrastructural immunohistochemical and DNA content analysis of lymphomas having features of interdigitating reticulum cells. Cancer 1988;61:1594-601.

11. Chan WC, Zaatari G. Lymph node interdigitating reticulum cell sarcoma. Am J Clin Pathol 1986;85:739-44.

12. Nakamura S, Koshikawa T, Kitoh K, et al. Interdigitating cell sarcoma: a morphologic and immunologic study of lymph node lesions in four cases. Pathol Int 1994;44:374-86.

13. Gould VE, Warren WH, Faber LP, Kuhn C, Franke WW. Malignant cells of epithelial phenotype limited to thoracic lymph nodes. Eur J Cancer 1990;26:1121-6.

14. Andriko JW, Kaldjian EP, Tsokos M, Abbondanzo SL, Jaffe ES. Reticulum cell neoplasms of lymph nodes: a clinicopathologic study of 11 cases with recognition of a new subtype derived from fibroblastic reticular cells. Am J Surg Pathol 1998;22:1048-58.

15. Chan AC, Serrano-Olmo J, Erlandson RA, Rosai J. Cytokeratin-positive malignant tumors with reticulum cell morphology: a subtype of fibroblastic reticulum cell neoplasm? Am J Surg Pathol 2000;24:107-16.

16. Schrock E, Veldman T, Padilla-Nash H, et al. Spectral karyotyping refines cytogenetic diagnostics of constitutional chromosomal abnormalities. Hum Genet 1997;101:255-62.

17. Harvell JD, Fulton R, Jones CD, Terris DJ, Warnke RA. Composite dendritic cell neoplasm (NOS) and small lymphocytic lymphoma. Appl Immuno Molec Morph 2000;8:322-8.

18. Raymond I, Al Saati T, Tkaczuk J, Chittal S, Delsol G. CNA.42, a new monoclonal antibody directed against a fixativeresistant antigen of follicular dendritic reticulum cells. Am J Pathol 1997;151:1577-85.

19. Starling GC, McLellan AD, Egner W, et al. Intercellular adhesion molecule- 3 is the predominant co-stimulatory ligand for leukocyte function antigen-1 on human blood dendritic cells. Eur J Immunol 1995;25:2528-32.

20. Ogata T, Yamakawa M, Imai Y, Takahashi T. Follicular dendritic cells adhere to fibronectin and laminin fibers via their respective receptors. Blood 1996;88:2995-3003.

21. Gunn MD, Ngo VN, Ansel KM, Ekland EH, Cyster JG, Williams LT. A B-cell-homing chemokine made in lymphoid follicles activates Burkitt's lymphoma receptor-1. Nature 1998;391:799-803.

22. Perez-Ordonez B, Erlandson RA, Rosai J. Follicular dendritic cell tumor: report of 13 additional cases of a distinctive entity. Am J Surg Pathol 1996;20:944-55.

23. Toyoda K, Taniguchi J, Kikawa K, et al. Follicular dendritic cell sarcoma: ultrastructural and immunohistochemical studies. Intern Med 2000;39:950-5.

24. Weiss LM, Berry GJ, Dorfman RF, et al. Spindle cell neoplasms of lymph nodes of probable reticulum cell lineage. True reticulum cell sarcoma? Am J Surg Pathol 1990;14:40514.

25. Schmelz M, Franke WW. Complexus adhaerentes, a new group of desmoplakin-containing junctions in endothelial cells: the syndesmos connecting retothelial cells of lymph nodes. Eur J Cell Biol 1993;61:274-89.

26. Fonseca R, Yamakawa M, Nakamura S, et al. Follicular dendritic cell sarcoma and interdigitating reticulum cell sarcoma: a review. Am J Hematol 1998;59:161-7.

27. Pallesen G, Myhre-Jensen O. Immunophenotypic analysis of neoplastic cells in follicular dendritic cell sarcoma. Leukemia 1987;1:549-57.

28. Ling NR, Hardie DL, Johnson GD, MacLennan IC. Origin and properties of soluble CD21 (CR2) in human blood. Clin Exp Immunol 1998;113:360-6.

29. Liu YJ, Xu J, de Bouteiller O, et al. Follicular dendritic cells specifically express the long CR2/CD21 isoform. J Exp Med 1997;185:165-70.

30. Fonseca R, Tefferi A, Strickler JG. Follicular dendritic cell sarcoma mimicking diffuse large cell lymphoma: a case report. Am J Hematol 1997;55:148-55.

31. Schriever F, Freedman AS, Freeman G, et al. Isolated human follicular dendritic cells display a unique antigenic phenotype. J Exp Med 1989;169:2043-58.

32. Doglioni C, Dell'Orto P, Zanetti G, Iuzzolino P, Coggi G, Viale G. Cytokeratin-immunoreactive cells of human lymph nodes and spleen in normal and pathological conditions. An immunocytochemical study. Virchows Arch A Pathol Anat Histopathol 1990;416:479-90.

33. Jones D, Jorgensen JL, Shahsafaei A, Dorfman DM. Characteristic proliferations of reticular and dendritic cells in angioimmunoblastic lymphoma. Am J Surg Pathol 1998;22: 956-64.

34. Gloghini A, Volpe R, Carbone A. Vimentin immunostaining in fibroblastic reticulum cells within human reactive and neoplastic lymphoid follicles. Hum Pathol 1990;21:792-8.

35. Gould VE, Bloom KJ, Franke WW, Warren WH, Moll R. Increased numbers of cytokeratin-positive interstitial reticulum cells (CIRC) in reactive, inflammatory and neoplastic lymphadenopathies: hyperplasia or induced expression? Virchows Arch 1995;425:617-29.

36. Pinkus GS, Warhol MJ, O'Connor EM, Etheridge CL, Fujiwara K. Immunohistochemical localization of smooth muscle myosin in human spleen, lymph node, and other lymphoid tissues. Unique staining patterns in splenic white pulp and sinuses, lymphoid follicles, and certain vasculature, with ultrastructural correlations. Am J Pathol 1986;123:440-53.

37. Tsunoda R, Nakayama M, Onozaki $\mathrm{K}$, et al. Isolation and long-term cultivation of human tonsil follicular dendritic cells. Virchows Arch B Cell Pathol Incl Mol Pathol 1990;59: 95-105.

38. Stahmer I, Zimmer JP, Ernst M, et al. Isolation of normal human follicular dendritic cells and CD4-independent in vitro infection by human immunodeficiency virus (HIV-1). Eur J Immunol 1991;21:1873-8.

39. Heinen E, Tsunoda R, Marcoty C, et al. Follicular dendritic cells: isolation procedures, short and long term cultures. Adv Exp Med Biol 1993;329:333-8. 
40. Freedman AS, Nadler LM. Cellular interactions within the germinal centre. Res Immunol 1991;142:232-6.

41. Bofill M, Akbar AN, Amlot PL. Follicular dendritic cells share a membrane-bound protein with fibroblasts. J Pathol 2000; 191:217-26.

42. Fliedner A, Parwaresch MR, Feller AC. Induction of antigen expression of follicular dendritic cells in a monoblastic cell line. A contribution to its cellular origin. J Pathol 1990;161:71-7.

43. Skibinski G, Skibinska A, Deckers M, James K. Tonsil stromal-cell lines expressing FDC-like properties: isolation, characterization, and interaction with B lymphocytes. Dev Immunol 1998;6:273-84.

44. Hollowood K, Stamp G, Zouvani I, Fletcher CD. Extranodal follicular dendritic cell sarcoma of the gastrointestinal tract. Morphologic, immunohistochemical and ultrastructural analysis of two cases. Am J Clin Pathol 1995;103:90-7.

45. Ryley NG, Bastert J, Ferguson DJ, Payne MJ. Follicular dendritic cell sarcoma of lymph node-report of fine needle aspiration (FNA) cytological appearances [see comments]. Cytopathology 1999;10:335-40. 